\title{
Interactive comment on "Long-term trends of surface ozone and its influencing factors at the Mt. Waliguan GAW station, China, Part 2: Variation mechanism and links to some climate indices" by Wanyun Xu et al.
}

Anonymous Referee \#1

Received and published: 4 August 2017

Long-term trends of surface ozone and its influencing factors at the Mt. Waliguan GAW station, China, Part 2: Variation mechanism and links to some climate indices. Author(s): Wanyun Xu et al. MS No.: acp-2017-483 MS Type: Research article Special Issue: Study of ozone, aerosols and radiation over the Tibetan Plateau (SOAR-TP) (ACP/AMT inter-journal SI)

General comments This paper explores the factors driving the observed ozone changes at Mt. Waliguan Observatory (WLG) using basically backward trajectory analysis and chemistry-climate model hindcast simulations (GFDL-AM3). The paper also 
deals links of ozone variability at WLG with the QBO, NAO, the East Asian summer monsoon (EASM), and the sunspot cycle. Although the paper addresses very interesting topics (probably too many issues in a single paper), complementary to that addressed in the companion paper (Xu et al., 2016), in a region of enormous interest such as the Tibetan Plateau, and using valuable data from a global GAW station such as WLG, the paper suffers from significant weaknesses that must be addressed with more credible and robust approaches.

The most important drawbacks are of methodological nature, and are briefly discussed below. Specific comments

1) The approach used for the backtrajectories dataset and climatology does not seem the most advisable to distinguish between ozone long-range transport from ozone produced by regional precursors. The use of the directions of only start-points (origin) of the trajectories into bins of $45^{\circ}$ is a very weak approximation. Air masses normally move among sectors along their entire trajectory (especially those of 7 days duration). So, it seems more reasonable to use some index accounting for the time of residence of the trajectory in each geographical sector. Bins of $45^{\circ}$ seem to be too narrow for 7 -day backtrajectories for which a great error / uncertainty in the geographical determination is associated.

2) The use of 1-day trajectories to estimate the impact of regional ozone sources and those of 7-day path (very long) as representative of ozone long-range transport are not well understood and not sufficiently justified. In fact, when the 1994-2013 climatology of air mass origins at WLG in the PBL and FT are depicted (Figure 1), the main patterns in the distribution of the air massesfrequency is quite similar for both regions (PBL and FT). Indeed, that means that the discrimination between PBL and FT air masses has not been satisfactorily achieved.

3) Nothing is said about the methodology used to determine the critical height of the back-trajectory in relation to the PBL height for each point of the airmass trajectory.

Printer-friendly version

Discussion paper
Interactive

comment 
4) In page 8 Lines 5-13; The results are inconsistent and, in some cases, contradictory. Section 3.1 is plenty of inconsistencies such as the following in page 8 lines 16-18:"The $\mathrm{t}=-168 \mathrm{~h}$ trajectory direction provides us information on the overall origin of the air-mass, while the trajectory direction calculated for $\mathrm{t}=-24 \mathrm{~h}$ should be able to reveal if the airmass passed over nearby polluted regions before arriving at the station", while in lines $26-27$, is said: "From the $\mathrm{t}=-168 \mathrm{~h}$ trajectory direction frequencies, it can be seen that the anthropogenic influence is negligible in all seasons"

5) Analyzing $24 \mathrm{~h}$ and 7-day trajectories, how it is possible to say that "....with PBL airmasses dominating during the day and FT air-masses during the night, which led to a clear diurnal variation of high nighttime and low daytime ozone concentrations". This situation, which is very realistic, probably overturns all the assumptions made for the establishment of the methodology of FT and PBL backtrajectories.

6) All of Section 3.1 should be reviewed using a consistent methodology.

7) In Section 3.2 is difficult to support a joint analysis of point observations in WLG with simulations of GFDL-AM3 with a resolution of 200X200 km2.

8) I do not see GFDL-AM3 captures the inter-annual variation of observed surface ozone anomaly, with the correlation coefficient ranging from 0.5 to 0.7 for spring, summer and autumn, as it is said.

9) The sentence "A stratospheric ozone tracer implemented in 30 GFDL-AM3 (O3Strat; Sect. 2.5) indicates that the stratospheric influence can explain $23 \%(r=0.48)$ of the observed ozone interannual variability in spring (Fig.4a) but contributes little to observed variability in other seasons" is quite speculative.

10) The trends on frequency of trajectories, by using only the geographical sector, where the starting point is 7 days before, it could give misleading results. However, potential trends in backtrajectories frequency constitutes a key point in the analysis and assessments of the paper.

Printer-friendly version

Discussion paper 
11) EACOt (page 11 Line 9) does not seem to have any bearing on the changing trend of ozone, according to Figure 5 and 6.

12) In sections 3.2 and 3.3., it is difficult to understand why the authors have not used in-situ ancillary observations to distinguish the impact of direct ozone transport from that formed from precursors, and ozone from upper troposphere from pollution-derived ozone. Authors have used in a very limited way carbon monoxide (CO) in Section 3.3 (this does not appear in section 2.1 Data) but they have not crossed $\mathrm{O} 3$ and CO data to discriminate the $\mathrm{O} 3$ origin, but they have used the $\mathrm{CO}$ and backtrajectories trends (??). Authors might have also used water vapour mixing-ratio or absolute humidity to discriminate high ozone from upper levels. On the contrary, the authors have used rough simulations whose uncertainty is not known.

13) In section 3.3, again the methodological approach used in the backtrajectory sectors might result in wrong results since air masses pass over different ozone precursors sources along their paths. Considering the start-point (origin) of the trajectory is too simplistic.

14) In section 4.1 (Stratosphere-to-troposphere transport and jet characteristics) the methodology approach is also quite weak. The authors use model simulations, when they could also/instead in-situ water vapour mixing ratio at WLG to discriminate upper troposphere (rather than stratospheric air masses) with the help of PV at a near WLG level. Unfortunately, the example given for March 30, 2012 is also not good since the values of $\mathrm{O} 3$ and $\mathrm{PV}$ do not correspond to upper troposphere air masses (and even less to stratospheric air masses). The $7 \mathrm{PVU}$ at $250 \mathrm{hPa}$ does not justify the impact of upper tropospheric air masses to WLG.

15) In section 4.1 an important conceptual issue it is not clear at all. The authors, when referring to STE air masses, mean to a quite jet or to baroclinic cut-off lows (or deep lows) associated to the position of the jet? It is is difficult to conceive the direct impact and of a quite jet on surface ozone at WLG, and if it so, the authors should demonstrate

Interactive 
this important result.

16) Finally, the link between ozone at WLG with different modes of atmospheric circulation (section 4.2) is not justified or explained in all the cases. The authors limit themselves to presenting a series of statistical relationships, in some cases with very low and non-significant correlations, between ozone and climatic indexes, without necessarily having a causal relationship. Authors should decide whether to maintain this section with the degree of development they have so poorly achieved. If they maintain the section, it should be significantly improved, discarding those indices that clearly have no direct relation to the ozone observed in WLG.

Technical corrections It does not make sense to go into details without having deeply addressed the changes proposed in the major comments. English should be significantly smoothed as it is difficult to understand the meaning of some sentences of the manuscript.

Interactive comment on Atmos. Chem. Phys. Discuss., https://doi.org/10.5194/acp-2017-483, 2017. 